\title{
Adaptive dynamics and technological change
}

\author{
Fabio Dercole ${ }^{\mathrm{a}, *}$, Ulf Dieckmann ${ }^{\mathrm{b}}$, Michael Obersteiner ${ }^{\mathrm{b}, \mathrm{c}}$, Sergio Rinaldi ${ }^{\mathrm{a}, \mathrm{b}}$ \\ ${ }^{a}$ DEI, Department of Electronics and Information, Politecnico di Milano, Via Ponzio 34/5, 20133 Milano, Italy \\ ${ }^{\mathrm{b}}$ IIASA, International Institute for Applied Systems Analysis, Schlossplatz 1, 2361 Laxenburg, Austria \\ ${ }^{\mathrm{c}}$ Department of Economics and Finance, IHS, Institute for Advanced Studies, A-1060 Vienna, Austria
}

\begin{abstract}
This paper is about the emergence of technological variety arising from market interaction and technological innovation. Existing products in the market compete with innovative ones resulting in a slow and continuous evolution of the underlying technological characteristics of successful products. When technological evolution reaches an equilibrium, it can either be an evolutionarily stable strategy (ESS), where marginally innovative products do not penetrate the market, or a branching point, where new products coexist along with established ones. Thus, technological branching can give rise to product variety. In the paper we first introduce adaptive dynamics (AD), a recently proposed theory of evolutionary processes, aiming at modeling various features of technological change. By separating the timescale typical of market competition processes from that on which marginal innovations drive technological change, $\mathrm{AD}$ formally describes products coevolution by means of ordinary differential equations. Then, a first application of AD in economics is presented and discussed in detail. The problem we discuss is intentionally very simple, in order to clearly exemplify all the steps of the analysis, but allows to draw the following intuitive conclusion: product variety is expected in market sectors characterized by a wide capacity to absorb different technologies and by competition-safe niches even for relatively similar products. The limitations of the AD approach, as well as some promising further applications in economics and social sciences, are briefly discussed at the concluding section. (C) 2007 Elsevier Ltd. All rights reserved.
\end{abstract}

Keywords: Adaptive dynamics; Market dynamics; Innovation dynamics; Characteristic trait; Technological branching; Product variety

\section{Introduction}

Technological change is a major driver of economic development (Burda and Wyplosz, 1997; Harberger, 1998). New growth theory has claimed the understanding of the implications of technological advancement for economic policy making mainly focusing on efficiency gains (see, for instance Romer, 1990; Grossman and Helpman, 1991; Aghion and Howitt, 1992; Kortum, 1997; Peretto, 1998; Segerstrom, 1998; Young, 1998). One of the fundamental empirical trends in economic development is the trend toward growing variety. Although some, like Schumpeter (1912), realized early on that variety in consumer goods is "one of the fundamental impulses that set and keep the

\footnotetext{
*Corresponding author. Tel.: + 3902 2399 3484; fax: + 390223993412

E-mail addresses: fabio.dercole@polimi.it (F. Dercole), dieckmann@iiasa.ac.at (U. Dieckmann), oberstei@iiasa.ac.at (M. Obersteiner), sergio.rinaldi@polimi.it (S. Rinaldi).
}

capitalist engine in motion", relatively little attention has traditionally been devoted to the systematic exploration of the nature of diversity in economics.

Diversity is variously argued to be a major factor in the fostering of innovation and growth, an important strategy for hedging against intractable uncertainty and ignorance, the principal means to mitigate the effects of "lock-in" under increasing returns and a potentially effective response to some fundamental problems of social choice. Grübler (1998) argues that technological diversity is both a means and a result of economic development. Saviotti (1996), a crucial contribution on the subject, establishes two explicit hypotheses linking variety to economic development: (1) the growth in variety is a necessary requirement for long-term economic development; (2) variety growth, leading to new sectors, and productivity growth in pre-existing sectors, are complementary and not independent aspects of economic development. Stirling (1998), who provides an excellent literature review on 
diversity in the economy, concludes that the concept of diversity (and especially technological diversity) is of considerable general significance in economics.

It is the purpose of this paper to propose a rigorous modeling framework describing the interaction of technology with its social and physical environment leading to technological diversity. In our opinion adaptive dynamics (AD), a general theory of evolutionary processes (Dieckmann and Law, 1996; Metz et al., 1996; Geritz et al., 1997, 1998), offers tools to explicitly study the process of technological change and its interaction with the market process. Viewed through the lenses of AD technological change is mainly based on a large number of small intentional or spontaneous innovations, recombinations and rearrangements of technological and economic characteristic traits. Firms compete in terms of the efficiency with which they produce or by changing products and processes. Efficiency gains as well as changes in products or processes are measured by "characteristic traits". When a new technological variant enters the market, it is subjected to severe selection by customers and other agents such as banks, courts of appeal, democratic vote, and so on. Under these circumstances and a few other technical assumptions discussed in the next section, AD predicts the following series of facts that one can often observe in real economies, at least at a stylized level.

1. Technological innovations are either rejected or win the competition with established products, thus becoming the new predominant type. A small variation of the technological characteristic traits is associated to each invasion and substitution event. The result is a slow and smooth evolution of the traits.

2. Evolution can slow down and approach an equilibrium, but it can also tend toward a cyclic or chaotic regime (Khibnik and Kondrashov, 1997). Moreover, it is not said that all evolutionary paths tend toward the same attractor: in other words, the long-term implications of the innovation process can strongly depend upon the innovation paths followed in the past. Finally, technological change can also transform particular products which in the past were predominant types into obsolete products which are swept out from the market.

3. Evolutionary equilibria can be terminal points of technological change where, typically, no marginal innovation can penetrate the market (Hamilton, 1967; Maynard Smith and Price, 1973; Maynard Smith, 1974, 1982; Nash, 1996). However, they can also be branching points, where the new variant can penetrate without substituting the old products. This technological branching explains the emergence of technological variety. Repeated branchings can give rise to rich clusters of products coexisting in the market.

4. The above processes of disappearance and emergence of specific technologies are largely influenced, if not dominated, by consumer behavior and other market conditions which act as the economic filter for innovations and either pull or suppress the diffusion of new technologies (see, e.g., Brooks, 1980; Hodgson, 1997; Kelm, 1997).

The paper is organized as follows. In the next section we present the general framework of AD by adapting it to the problem of technological change. In particular, we show why the separation between market and technological innovation timescales is needed to technically derive from AD principles a formal mathematical machinery, the socalled AD canonical equation. Then, we present the first original application of $\mathrm{AD}$ to a specific problem of technological change. The problem we discuss is intentionally very simple, in order to obtain the AD equation in closed form and point out from it the properties mentioned above. Finally, in the conclusion we discuss the limitation and the advantages of the AD approach and give a short overview of the wide scope of evolutionary phenomena that AD could potentially explain in economics and social sciences.

\section{AD: an overview}

In this section we present the general framework of $\mathrm{AD}$ by focusing our attention on a specific market with $N$ coexisting products (namely entities, artifact's or services), hereafter called established products. The starting point of $\mathrm{AD}$ is the description of the dynamics of the product densities in the market (e.g., the number of items owned by 1000 persons) through a system of ordinary differential equations (ODEs). The market transient dynamics is assumed to expire on a timescale which is fast compared to that at which innovations challenge the market. These two timescales are called market and innovation timescales, respectively, and their separation is the main assumption of AD. This somehow limits AD to the analysis of slow innovation processes and/or highly competitive markets. However, as we will see in the following sub-sections, this limitation allows us to clearly distinguish the market dynamics from technological change and to identify the nature of their coupling.

More precisely, AD is based on four technical assumptions:

(a) Each product is identified by a characteristic trait (simply trait in the following) quantifying its features by a positive real number. We assume that products with a higher trait value are technologically more advanced. However, this does not imply that more advanced products are necessarily preferred by consumers, since elasticities of the products as well as budgetary constraints are also important. Examples of characteristic traits are the waterproof characteristic for watches, the Internet capabilities for mobile phones or the graphical user interface features of a software. 
(b) In the absence of innovations, product densities tend to a market equilibrium. The timescale on which product densities vary is called market timescale.

(c) Innovation events are rare on the market timescale, i.e., they occur on a longer timescale that we call innovation timescale. In other words, we assume that market clearing occurs instantaneously on the innovation timescale. The separation between the market and innovation timescales allows one to assume that when an innovative product appears the established products are at market equilibrium, and the market is challenged by one innovation at a time.

(d) Innovations are small, i.e., the trait of the innovative product differs only slightly from the trait of one of the established products. We therefore consider the case of "marginal" innovation, where innovations are new but similar versions of the existing products.

The principles and methods of $\mathrm{AD}$ are presented in the founding papers of Metz et al. (1996) and Geritz et al. (1997, 1998), and in Dieckmann and Law (1996), Geritz et al. (2002), Geritz (2005), Champagnat et al. (2006) (see also Dercole and Rinaldi, 2008, for a comprehensive treatment). We now discuss the core of the theory by adapting it to the context of technological change.

Denote by $n_{1}, \ldots, n_{N}$ and $x_{1}, \ldots, x_{N}$ the densities and traits of the $N$ established products. For notational convenience, we often indicate these densities and traits as vectors $n$ and $x$. On the market timescale (fast market dynamics), the traits are constant while the densities vary in accordance with $N$ ODEs of the form

$\dot{n}_{j}=n_{j} F_{j}\left(n_{1}, \ldots, n_{N}, x_{1}, \ldots, x_{N}\right), \quad j=1, \ldots, N$,

where $F_{j}$ is the relative diffusion rate of the $j$ th product and $\dot{n}_{j}$ is the time derivative of $n_{j}$. For example, if $N=1$, there is a single product in the market and its diffusion can be modeled through the classical logistic growth equation (see, e.g., Fisher and Pry, 1971)

$\dot{n}_{1}=r\left(x_{1}\right) n_{1}\left[1-\frac{n_{1}}{K\left(x_{1}\right)}\right]$,

where $r\left(x_{1}\right)$ is the maximum diffusion rate and $K\left(x_{1}\right)$ is the market equilibrium density.

In the following, model (1) is assumed to have a stable and strictly positive equilibrium $\bar{n}(x)$, called market equilibrium, for each $x$ belonging to a region of the trait space called stationary coexistence region. We also assume that $\bar{n}(x)$ is globally stable in the positive orthant. This condition is not necessary, but it simplifies the discussion (see Dercole et al., 2002; Dercole and Rinaldi, 2002 for relevant exceptions and Dercole et al., 2006 for a case of cyclic coexistence).

We now show why the four stylized facts mentioned in the Introduction can be derived from AD theory.

\subsection{Canonical equation}

The dynamics of the traits, hereafter called innovation dynamics, should reflect the characteristics of the innovation and the market selection processes, which, however, are not included in model (1). In order to describe the competition between the established products and an innovative product, we split the $i$ th product into two subproducts (established and innovative) with densities $n_{i}$ and $n_{i}^{\prime}$ and traits $x_{i}$ and $x_{i}^{\prime}$, so that the model reads

$\dot{n}_{j}=n_{j} f_{j}\left(n, n_{i}^{\prime}, x, x_{i}^{\prime}\right), \quad j=1, \ldots, N$,

$\dot{n}_{i}^{\prime}=n_{i}^{\prime} f_{i}^{\prime}\left(n, n_{i}^{\prime}, x, x_{i}^{\prime}\right)$.

Obviously, model (2) contains more information than model (1). Indeed, model (1) can be immediately derived from model (2) by disregarding the equation of the innovative product and letting $n_{i}^{\prime}=0$, thus obtaining

$F_{j}(n, x)=f_{j}\left(n, 0, x, x_{i}^{\prime}\right), \quad j=1, \ldots, N$,

where the function $f_{j}\left(n, 0, x, x_{i}^{\prime}\right)$ does not depend on $x_{i}^{\prime}$. The functions $f_{j}$ and $f_{i}^{\prime}$, at the right-hand sides of model (2) enjoy the following structural properties:

$$
\begin{aligned}
& f_{j}\left(n, n_{i}^{\prime}, x, x_{i}\right)=F_{j}\left(n_{1}, \ldots, n_{i-1}, n_{i}+n_{i}^{\prime}, n_{i+1}, \ldots, n_{N}, x\right), \\
& j=1, \ldots, N, \\
& \begin{aligned}
f_{i}^{\prime}\left(n, n_{i}^{\prime}, x, x_{i}\right) & =f_{i}\left(n, n_{i}^{\prime}, x, x_{i}\right) \\
& =F_{i}\left(n_{1}, \ldots, n_{i-1}, n_{i}+n_{i}^{\prime}, n_{i+1}, \ldots, n_{N}, x\right),
\end{aligned}
\end{aligned}
$$

because, if $x_{i}^{\prime}=x_{i}$, the established and innovative products do not differ, so that only the total density $\left(n_{i}+n_{i}^{\prime}\right)$ matters. Moreover

$f_{i}^{\prime}\left(n, n_{i}^{\prime}, x, x_{i}^{\prime}\right)=f_{i}\left(n^{\prime}, n_{i}, x^{\prime}, x_{i}\right)$,

where

$n^{\prime}=\left(n_{1}, \ldots, n_{i-1}, n_{i}^{\prime}, n_{i+1}, \ldots, n_{N}\right)$

and

$x^{\prime}=\left(x_{1}, \ldots, x_{i-1}, x_{i}^{\prime}, x_{i+1}, \ldots, x_{N}\right)$,

because any one of the two sub-products can be considered as innovative, provided the other is considered as established. Notice that property (4) is implied by properties (3) and (5).

We can now derive how the traits vary in time. Since model (1) is, by assumption, at its equilibrium $\bar{n}(x)$ when an innovation occurs, the initial conditions in model (2) are $\left(\bar{n}(x), n_{i}^{\prime}\right)$. Thus, $\dot{n}_{i}^{\prime}>0$, i.e., the innovative product penetrates the market, if $f_{i}^{\prime}\left(\bar{n}(x), n_{i}^{\prime}, x, x_{i}^{\prime}\right)>0$, which is guaranteed if $f_{i}^{\prime}\left(\bar{n}(x), 0, x, x_{i}^{\prime}\right)>0$ since $n_{i}^{\prime}$ is small (the innovative product is initially present in a few items). The function $f_{i}^{\prime}\left(\bar{n}(x), 0, x, x_{i}^{\prime}\right)$, called invasion fitness, is strategically important and is abbreviated, in the following, as $\bar{f}_{i}^{\prime}\left(x, x_{i}^{\prime}\right)$, i.e.,

$\bar{f}_{i}^{\prime}\left(x, x_{i}^{\prime}\right)=f_{i}^{\prime}\left(\bar{n}(x), 0, x, x_{i}^{\prime}\right)$. 
Notice that property (4) implies that the invasion fitness vanishes for $x_{i}^{\prime}=x_{i}$, i.e.,

$\bar{f}_{i}^{\prime}\left(x, x_{i}\right)=0$,

because the established products are at equilibrium.

The invasion fitness $\bar{f}_{i}^{\prime}$ represents the relative diffusion rate of a few innovative items in the market set by the established products. Innovations originate by chance but their fate depend on their competitiveness, i.e., on their capacity to penetrate the market. Competitiveness is, therefore, a concept relevant on the market timescale, that necessarily depends on the innovative trait $x_{i}^{\prime}$, as well as on the current market conditions, which are defined by the established product traits $x$. In other words, the invasion fitness of the novel product provides a summary of the underlying market selection process. As we shall see in the rest of the section, such a summary and a proper stochastic description of the innovation process are necessary and sufficient to make the step to macro-evolutionary considerations on the innovation timescale.

If $\bar{f}_{i}^{\prime}\left(x, x_{i}^{\prime}\right)<0$, it follows from model (2) that just after the innovation $\dot{n}_{i}^{\prime}<0$, i.e., the innovative product does not penetrate and actually exits the market. Thus, the final result is still a set of $N$ established products with traits $x$ and densities $\bar{n}(x)$. By contrast, if $\bar{f}_{i}^{\prime}\left(x, x_{i}^{\prime}\right)>0$, the innovative product initially penetrates and, under very general conditions, the $i$ th established product exits the market, being replaced by its new version. Thus, in this case, the trajectory of model (2) originating at $\left(\bar{n}(x), n_{i}^{\prime}\right)$ ends at

$\left(\bar{n}_{1}\left(x^{\prime}\right), \ldots, \bar{n}_{i-1}\left(x^{\prime}\right), 0, \bar{n}_{i+1}\left(x^{\prime}\right), \ldots, \bar{n}_{N}\left(x^{\prime}\right), \bar{n}_{i}\left(x^{\prime}\right)\right)$,

i.e., the final result is a new set of $N$ established products with traits $x^{\prime}$ and densities $\bar{n}\left(x^{\prime}\right)$ (see (6)). In other words, each innovation brings a new trait into the market, but competition between established and innovative products selects the winner, namely the trait that remains in the market.

The conditions under which the innovative product replaces the established one are known as the invasion implies substitution principle (see Dercole and Rinaldi, 2008 , and references therein, for a proof) and require that $\bar{n}(x)$ is continuous with respect to $x_{i}$ at $x$ and

$\left.\frac{\partial \bar{f}_{i}^{\prime}}{\partial x_{i}^{\prime}}\right|_{x_{i}^{\prime}=x_{i}}\left(x_{i}^{\prime}-x_{i}\right)>0$.

Notice that the equilibrium (8) exists because, by assumption, $\bar{n}(x)$ is continuous with respect to $x_{i}$ at $x$. By developing $\bar{f}_{i}^{\prime}$ in Taylor series with respect to $x_{i}^{\prime}$, and recalling that innovations are small (i.e., $x_{i}^{\prime}$ differs only slightly from $x_{i}$ and $n_{i}^{\prime}(0)$ is very small), one obtains

$\left.\dot{n}_{i}^{\prime}(0) \simeq n_{i}^{\prime}(0) \frac{\partial \bar{f}_{i}^{\prime}}{\partial x_{i}^{\prime}}\right|_{x_{i}^{\prime}=x_{i}}\left(x_{i}^{\prime}-x_{i}\right)$,

where $t=0$ is the time at which the innovation occurs. Thus, condition (9) implies $\dot{n}_{i}^{\prime}(0)>0$, i.e., initial penetration of the innovative product.
The quantity

$\left.\frac{\partial \bar{f}_{i}^{\prime}}{\partial x_{i}^{\prime}}\right|_{x_{i}^{\prime}=x_{i}}$

is called selection derivative, and the vector with components (11), $i=1, \ldots, N$, is called selection gradient. Thus, as long as the selection gradient does not vanish, the dynamics of the traits are characterized by

$\dot{x}_{i}\left\{\begin{array}{l}>0 \text { if }\left.\frac{\partial \bar{f}_{i}^{\prime}}{\partial x_{i}^{\prime}}\right|_{x_{i}^{\prime}=x_{i}}>0, \\ <0 \text { if }\left.\frac{\partial \bar{f}_{i}^{\prime}}{\partial x_{i}^{\prime}}\right|_{x_{i}^{\prime}=x_{i}}<0,\end{array} \quad i=1, \ldots, N\right.$,

where $\dot{x}_{i}$ is the time derivative of $x_{i}$ on the innovation timescale, which measures technological change in the $i$ th product. The selection gradient therefore gives the direction of technological change and describes a continuous feedback between innovation and competition processes. In fact, technological change $\dot{x}_{i}$ depends on consumption patterns which develop on the market timescale in accordance with the competition model (2), and which are summarized by the invasion fitness (7). In turn, consumption patterns are affected by the current technologies, represented by the trait vector $x$.

The process of innovation and selection can be further specified by making suitable assumptions on the frequency and distribution of innovations. The speed of innovation is influenced by three primary factors: how often an innovation occurs; how large is the trait variation caused by an innovation; and how likely it is that an initially scarce set of new products penetrates the market. By suitably modeling these three factors, one can prove that if innovations are sufficiently small, the innovation process proceeds by a large number of subsequent penetrations and substitutions and can be approximated by the following system of ODEs (Dieckmann and Law, 1996; Champagnat et al., 2006; Dercole and Rinaldi, 2008):

$\dot{x}_{i}=\left.\frac{1}{2} \mu_{i}(x) \bar{n}_{i}(x) \sigma_{i}^{2}(x) \frac{\partial \bar{f}_{i}^{\prime}}{\partial x_{i}^{\prime}}\right|_{x_{i}^{\prime}=x_{i}}, \quad i=1, \ldots, N$,

called the canonical equation of AD. With reference to the $i$ th product, $\mu_{i}$ is proportional to the probability of an innovation per event of production of a new item, $\mu_{i} \bar{n}_{i}$ is thus proportional to the number of innovations that are put on the market per unit of time (on the innovation timescale), and $\sigma_{i}^{2}$ is the variance of the innovative step $x_{i}^{\prime}-x_{i}$, assumed to be symmetrically distributed around zero. The probability of penetration consists of two factors. First, as long as the selection derivative (11) is positive [negative], only innovations with trait value larger [smaller] than that of the established product can penetrate; in other words, half of the innovations are always at selective disadvantage. This leads to the factor $\frac{1}{2}$ in the canonical 
equation. Second, innovations at selective advantage may be accidentally lost in the initial phase of invasion when they are present only in a few items. The probability of not being lost is proportional to the selective advantage of the innovation as measured by the selection derivative (11).

In conclusion, we have obtained the following model:

$\dot{x}_{i}=G_{i}\left(x_{1}, \ldots, x_{N}\right), \quad i=1, \ldots, N$

with

$G_{i}(x)=\left.\frac{1}{2} \mu_{i}(x) \bar{n}_{i}(x) \sigma_{i}^{2}(x) \frac{\partial \bar{f}_{i}^{\prime}}{\partial x_{i}^{\prime}}\right|_{x_{i}^{\prime}=x_{i}}$.

Such a model describes the technological coevolution of $N$ products driven by rare marginal innovations. At any time on the innovation timescale the products coexist at the market equilibrium $\bar{n}(x)$ corresponding to the current technologies $x$. Technological evolution therefore entrains the evolution of the market equilibrium.

\subsection{Long-term scenarios}

In contrast to prevailing economic theories that focus on the properties of the equilibrium, the $\mathrm{AD}$ approach is based on a dynamical framework which accounts for the full dynamics of technological change and its concomitant changes in the market, including, for instance, the description of the evolutionary transient. Notice that the evolutionary model (13) is an autonomous system of ODEs. Thus, economic systems perpetually reshape themselves, thereby changing their own technological basis, which is condensed in the trait vector $x$.

It is important to remark that the AD canonical equation models a coevolutionary context where innovation in one product leads to coevolutionary changes in all other related products in the market under consideration. The importance of this mutual interactions is best described by Ziman (2000) who says “... material artifact's cannot be considered in isolation from their cognitive and social correlates... as the artifact changes, so does the cloud of ideas and social activities that surround it".

Moreover, model (13) is in general nonlinear, which means that the interactions between technology and its market are capable to give rise to a rich set of scenarios. In the simplest evolutionary scenario one can imagine (Fig. 1A), technological change converges to a particular combination of the traits, no matter what the initial conditions are. This is the typical situation where a set of products or services have reached a so high standard to become practically unbeatable, like the Chinese, French,
A

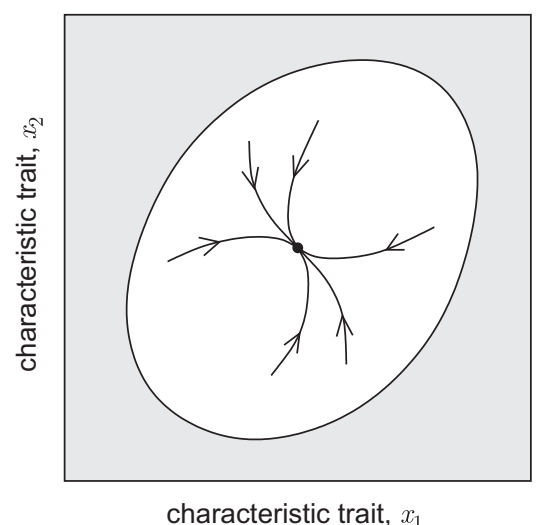

C

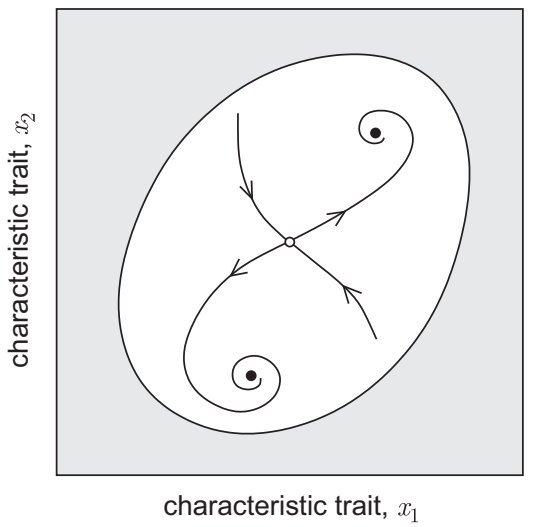

B

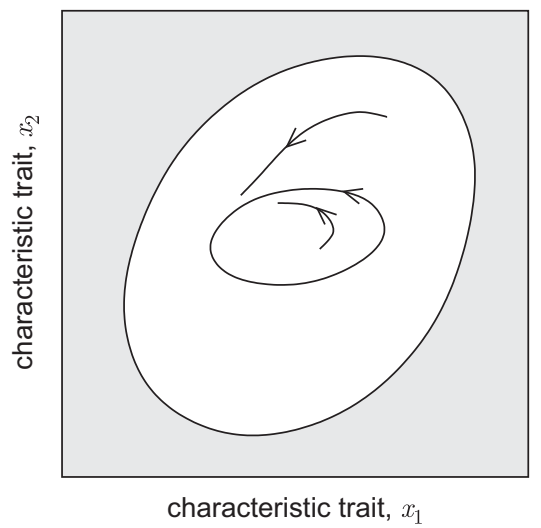

D

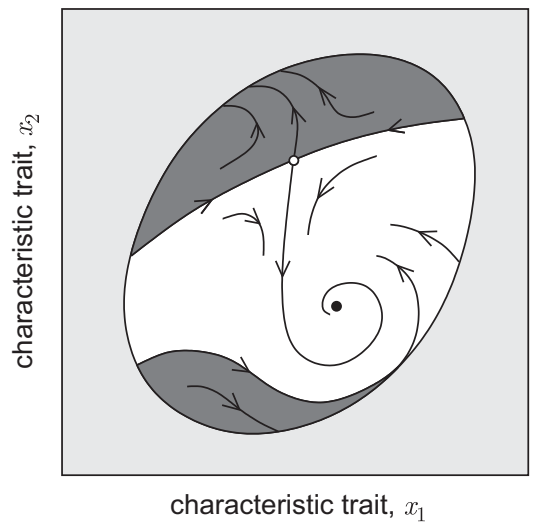

Fig. 1. Possible evolutionary scenarios: convergence toward an equilibrium (A) or a limit cycle (B) from any initial conditions; alternative equilibria (C); evolutionary extinction of a product (D). 
and Italian cuisine. A wilder scenario is that of never ending ups and downs of the traits, like those repeatedly recorded in the fashion market (see, e.g., the skirt length of women's formal evening dresses reconstructed by Lowe and Lowe, 1990, from the analysis of fashion magazines over two centuries). In these cases the traits evolve either toward a limit cycle (Fig. 1B) or toward a strange attractor as discussed in Khibnik and Kondrashov (1997). Another case of interest (Fig. 1C) is that of alternative equilibria (or attractors). This means that the long-term implications of the innovation process can depend upon the innovation paths followed in the past. Such path dependency could for example explain divergence phenomena discussed in development economics, where some developing countries seem to fall into a technological and economic underdevelopment trap, while, industrialized countries converge to a high technological level. Finally, it can also happen (Fig. 1D) that some evolutionary trajectories reach the boundary of the coexistence region where one of the products cannot be sustained in the market. This is, for example, what happened to the telex technology and what is expected to happen in the near future to the fax technology.

\subsection{Emergence of diversity}

We call evolutionary equilibrium a constant solution of the canonical equation (12), i.e., a set of traits $\bar{x}$ at which all selection derivatives (11) vanish

$\left.\frac{\partial \bar{f}_{i}^{\prime}}{\partial x_{i}^{\prime}}\right|_{\substack{x_{i}^{\prime}=\bar{x}_{i} \\ x=\bar{x}}}=0, \quad i=1, \ldots, N$.

Of course, evolutionary equilibria can be either stable or unstable equilibria of the canonical equation (12). If innovation dynamics have found a halt at a stable evolutionary equilibrium $\bar{x}$, where the first-order term of $\dot{n}_{i}^{\prime}(0)$ vanishes (see Eq. (10)), in order to establish if an innovation is initially successful or not one can develop $\bar{f}_{i}^{\prime}$ in Taylor series up to the second-order term, thus obtaining

$\left.\dot{n}_{i}^{\prime}(0) \simeq n_{i}^{\prime}(0) \frac{\partial^{2} \bar{f}_{i}^{\prime}}{\partial x_{i}^{\prime 2}}\right|_{\substack{x_{i}^{\prime}=\bar{x}_{i} \\ x=\bar{x}}}\left(x_{i}^{\prime}-x_{i}\right)^{2}$.

The result is that the innovation initially penetrates if

$\left.\frac{\partial^{2} \bar{f}_{i}^{\prime}}{\partial x_{i}^{\prime 2}}\right|_{\substack{x_{i}^{\prime}=\bar{x}_{i} \\ x=\bar{x}}}>0$,

no matter if the trait value $x_{i}^{\prime}$ is larger or smaller than the established trait $\bar{x}_{i}$. If condition (14) holds with the opposite inequality sign for all $i=1, \ldots, N$, then $\bar{x}$ is protected against invasion and is, therefore, a so-called evolutionarily stable strategy (ESS) as defined in evolutionary game theory (Hamilton, 1967; Maynard Smith and Price, 1973; Maynard Smith, 1974, 1982; Nash, 1996). In other words, technological evolution by means of small innovations can drive an economic system to a terminal point of the evolutionary process, a trap from which the system can possibly escape only by exogenously injecting radically different products into the market.

Understanding the long-term consequences of an invasion at $\bar{x}$ is not an easy problem since we cannot rely on the invasion implies substitution principle, which indeed does not hold at an evolutionary equilibrium. However, Geritz et al. (2002) have shown that it is not possible that an initially penetrating innovative product is ruled out from the market in the long term. Thus, only two possibilities remain: either the innovative product substitutes the established product or it coexists with it at a stable and strictly positive market equilibrium. In accordance with the verbal definition given at point 3 of Section $1, \bar{x}$ is a branching point if

- it is a stable evolutionary equilibrium;

- the innovative product coexists with the established product, thus becoming an established product itself with density $n_{N+1}$ and trait $x_{N+1}$;

- the traits $x_{i}$ and $x_{N+1}$ are initially very close but, then, diverge in accordance with the new $(N+1)$-dimensional canonical equation.

Geritz et al. (1997, 1998) have shown that if $\bar{n}(x)$ is continuous at a stable evolutionary equilibrium $\bar{x}$, then the coexistence between innovative and established products is possible when

$\left.\frac{\partial^{2} \bar{f}_{i}^{\prime}}{\partial x_{i} \partial x_{i}^{\prime}}\right|_{\substack{x_{i}^{\prime}=\bar{x}_{i} \\ x=\bar{x}}}<0$,

while the invasion condition (14) also guarantees the initial divergence of $x_{N+1}$ from $x_{i}$. Thus, in conclusion, a stable evolutionary equilibrium $\bar{x}$ is a branching point if, for some $i$, conditions (14) and (15) are satisfied. If the branching conditions (14) and (15) hold for more than one product, it is a matter of chance which product will branch first.

Technological branching occurs when the selective forces acting on the market first allow the coexistence of two slightly different types of products and then become repulsive, therefore favoring the diversification of two technologies originating from the same trait. Think, for example, to mobile and fixed phones: the first mobile phones were heavy car phones, different from fixed phones only for the presence of an antenna instead of a wire.

Notice that there are evolutionary equilibria which are neither ESSs nor branching points. Indeed, it can be shown (see Dercole and Rinaldi, 2008) that an innovative product can penetrate the market and substitute the corresponding established product, thus leading to a new trait assembly $x$ close to $\bar{x}$; but at this new trait composition the canonical equation (12) holds and, if $\bar{x}$ is stable, then $x$ converges back to $\bar{x}$, which is, then, a terminal point of the evolutionary process, even if it is not protected against penetration. For this reason we refer to stable ESSs and to 
this subset of stable evolutionary equilibria as evolutionarily terminal strategies.

After a branching has occurred in the $i$ th product, the market is composed of $(N+1)$ diversified products. Thus, one can derive the new $(N+1)$-dimensional canonical equation and repeat the analysis for the new market. If, again, technological change will evolve toward a branching point, the result will be a market with $(N+2)$ diversified products, an so on. Since no limit exists on the number of possible repeated branchings there is room for the formation of rich clusters of products. Long sequences of technological branchings are empirically evident in almost every market segment. Consumers worldwide can witness that an increasing number of products that match their expectations are available on the market (see, e.g., Grübler, 1998; Saviotti, 2001). For example, Ausubel (1990) showed that the average number of items on sale in a typical large US supermarket has increased from 2000 in 1950 to 18000 items in the 1990s.

\subsection{Exogenous factors}

The market competition model (2) and the frequency and distribution of innovations depend upon exogenous factors like consumer preferences, social and political structures, international relationships, availability of natural resources, and many others. In order to simplify the analysis, these factors can be left out from the model, but they can also be explicitly included and measured through some strategic parameter. In this case, as we will explicitly see in the next section, the canonical equation (12) depends upon a set of parameters, each with a specific economic interpretation. The role played by exogenous factors on the dynamics of technological change can then be identified by studying the canonical equation for all possible values of the exogenous parameters. This naturally calls for numerical bifurcation analysis (Kuznetsov, 1998), which is the most powerful technique for identifying the long-term consequences of parameter perturbations in ODEs models.

\subsection{Marginal innovations vs. major breakthroughs}

Before presenting an explicit application of $\mathrm{AD}$ in economics, it is worth stressing that the analysis described until now applies only to marginal innovations. In the case of a radical innovation (e.g., a revolutionary idea or a new import/ export protocol), namely when the innovative product trait is remarkably different from all other traits in the market, the outcome of the competition must be established by means of model (2). Once the new market equilibrium has been determined, the method of analysis discussed in this section can be used again to detect the consequences of new marginal innovations. Thus, the process of technological change, described by $\mathrm{AD}$ as a continuous process due to marginal innovations, is punctuated from time to time by major breakthroughs. Moreover, radically innovative products can penetrate the market without substituting the previous established products. Thus, the AD approach interestingly shows that the emergence of new products can be attributed to both marginal and radical innovation events. While it is rather obvious, as noted already by Schumpeter (1912), that radical innovations can generate product diversity, it is less obvious that product diversification can emerge through technological branching of incremental innovation steps. Thus, technological branching helps explaining increasing product diversity in a world that is dominated by incremental innovations.

\section{A simple example of technological branching}

We now present the first application of $\mathrm{AD}$ in economics. The problem we consider is intentionally simple in order to obtain the AD canonical equation in closed form and clearly identify the stylized properties mentioned in the first section. Although the model is far from being empirically testable, it provides some insights on the market conditions which favor technological branching and the emergence of product clusters.

We assume that different products $j=1, \ldots, N$, characterized by a single technological trait $x_{j}$, compete in the market according to the following model:

$\dot{n}_{j}=r\left(x_{j}\right) n_{j}\left[1-\frac{1}{K\left(x_{j}\right)} \sum_{l=1}^{N} \alpha\left(x_{j}, x_{l}\right) n_{l}\right], \quad j=1, \ldots, N$.

Model (16) is the simplest type of competition model (Hofbauer and Sigmund, 1998), where the relative diffusion rate $\dot{n}_{j} / n_{j}$ of the $j$ th product is a linear combination of all product densities. The functions $r\left(x_{j}\right), K\left(x_{j}\right)$, and $\alpha\left(x_{j}, x_{l}\right)$ describe the market environment and have the following economic interpretation. The function $r\left(x_{j}\right)$ is the maximum diffusion rate of the $j$ th product, which is realized only when the product is present in the market in small quantities ( $n_{j}$ very small) and there are no competitors $\left(n_{l}=0\right.$ for all $\left.l \neq j\right)$. The function $r\left(x_{j}\right)$ is therefore a theoretical measure of the penetration power of the product in an empty market. Similarly, functions $K\left(x_{j}\right)$ and $\alpha\left(x_{j}, x_{l}\right)$, respectively, measure the capacity of the market of absorbing technology $x_{j}$ and the competitive interactions between technologies $x_{j}$ and $x_{l}$. In particular, by scaling function $\alpha\left(x_{j}, x_{l}\right)$, we can disentangle the two measure. In fact, by imposing $\alpha\left(x_{j}, x_{j}\right)=1$ for all $j=1, \ldots, N$, one can easily see from (16) that $K\left(x_{j}\right)$ is the equilibrium density reached by the $j$ th product penetrating an empty market. Thus, $K\left(x_{j}\right)$ gives the product density absorbable by the market, and will be hereafter called absorptive capacity, while the competition function $\alpha\left(x_{j}, x_{l}\right)$ measures the reduction of the rate of diffusion of the $j$ th product due to the presence of the $l$ th competitor.

Model (16) has, generically, a unique strictly positive equilibrium satisfying the following system of $N$ linear algebraic equations:

$\sum_{l=1}^{N} \alpha\left(x_{j}, x_{l}\right) \bar{n}_{l}(x)=K\left(x_{j}\right), \quad j=1, \ldots, N$. 
Model (16) is quite special because it describes a purely competitive market. However, the analysis performed in the following can certainly be extended to a wide spectrum of behavioral interactions, ranging from competition to cooperation. Various notions of Homo reciprocans and Homo economicus could therefore be modeled, reflecting certain social mechanisms and institutions that punish anti-social behavior (Boyd and Richerson, 1992; Fehr and Gächter, 1998) but also reward image scoring (Nowak and Sigmund, 1998).

Let us assume that $r$ is independent of the trait and that the absorptive capacity and competition functions are lognormal, i.e.,

$K\left(x_{j}\right)=K_{0} \exp \left[-\frac{1}{2 \sigma_{K}^{2}}\left(\ln \frac{x_{j}}{x_{0}}\right)^{2}\right]$,

$\alpha\left(x_{j}, x_{l}\right)=\exp \left(\frac{\ln ^{2} \beta}{2 \sigma_{\alpha}^{2}}\right) \exp \left[-\frac{1}{2 \sigma_{\alpha}^{2}}\left(\ln \frac{x_{l}}{\beta x_{j}}\right)^{2}\right]$,

where $K_{0}, x_{0}, \sigma_{K}, \beta, \sigma_{\alpha}$ are constant positive parameters. Functions (18) and (19) and their control parameters can be economically interpreted as follows.

Three parameters, namely $K_{0}, x_{0}$, and $\sigma_{K}$, characterize the absorptive capacity function (18), which is bell shaped and peaks at some intermediate trait, given by $x_{0}$. Thus, in a single product market, $x_{0}$ is the technology which is most absorbable, while the equilibrium density of a technologically very poor or very sophisticated product vanishes with a sensitivity controlled by $\sigma_{K}$. High or low sensitivity (small and large values of $\sigma_{K}$ ), respectively, represent market structures where products concentrate around the technological characteristic trait $x_{0}$ or where consumers are to a large degree indifferent to different products satisfying a specific need. Graphically (see Fig. 2A) $\sigma_{K}$ is a measure of the wideness of the bell shaped graph of the absorptive capacity function.

The competition function (19) depends only upon the ratio $x_{j} / x_{l}$ of its arguments and tends to zero when such a ratio tends either to zero or to infinity, reflecting the fact that very diversified products compete only weakly (e.g., Ferrari and Fiat in the car market). Two parameters, namely $\beta$ and $\sigma_{\alpha}$, control the shape of the competition function. For $\beta=1$, competition is symmetric, i.e., $\alpha\left(x_{j}, x_{l}\right)=\alpha\left(x_{l}, x_{j}\right)$ and $\alpha\left(x_{j}, x_{l}\right)$ is maximum (and equal to one, recall the scaling property $\left.\alpha\left(x_{j}, x_{j}\right)=1\right)$ for $x_{j}=x_{l}$. Thus, two different technologies $x_{j} \neq x_{l}$ mutually affect each other with the same competition strength, and competition gets harsher as the two technologies are similar. By contrast, for $\beta \neq 1$, competition is asymmetric and $\alpha\left(x_{j}, x_{l}\right)$ is maximum for $x_{l}=\beta x_{j}$ (see Eq. (19) and Fig. 2B). This implies that for $\beta>1$ products with higher technological content tend to have a competitive advantage. In fact, the rate of diffusion of the $j$ th product is maximally depleted by competitors with trait $x_{l}=\beta x_{j}>x_{j}$, which, in turn, are mildly affected from the $j$ th product, since $\alpha\left(\beta x_{j}, x_{j}\right)<1<\alpha\left(x_{j}, \beta x_{j}\right)$. Analogously, for $\beta<1$ products with less technological content are better competitor. The parameter $\sigma_{\alpha}$ controls the sensitivity of the strength of competition with respect to the ratio of the technological traits of competing products. High sensitivity (i.e., small $\sigma_{\alpha}$ ) means that only very similar products compete, while if $\sigma_{\alpha}$ is large competition is high even between quite different products. Graphically (see Fig. 2B) $\sigma_{\alpha}$ is a measure of the wideness of the bell shaped graph representing the competition function with respect to the technological trait $x_{l}$.

Consider now the case of a market with a single established product and denote by $n_{1}^{\prime}$ and $x_{1}^{\prime}$ the density and trait of the innovative product. From Eqs. (7), (11), (16) and (17), straightforward algebra yields the following expressions for the market equilibrium $\bar{n}_{1}\left(x_{1}\right)$, the invasion fitness $\bar{f}_{1}^{\prime}\left(x_{1}, x_{1}^{\prime}\right)$, and the selection derivative:

$$
\bar{n}_{1}\left(x_{1}\right)=K\left(x_{1}\right) \text {, }
$$

$\bar{f}_{1}^{\prime}\left(x_{1}, x_{1}^{\prime}\right)=r\left[1-\frac{\alpha\left(x_{1}^{\prime}, x_{1}\right) K\left(x_{1}\right)}{K\left(x_{1}^{\prime}\right)}\right]$,
A

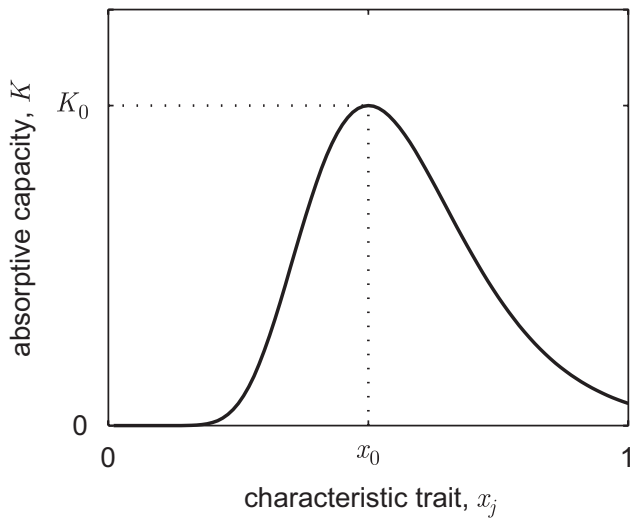

B

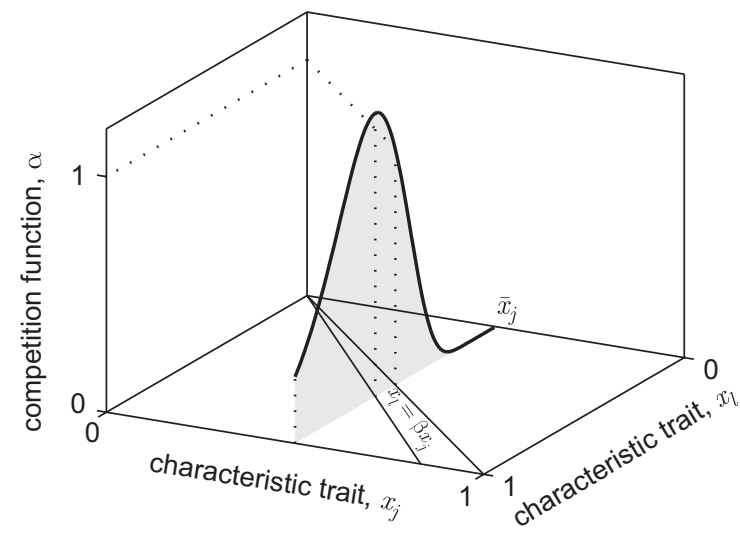

Fig. 2. (A) The absorptive capacity function; parameter values $K_{0}=1000, x_{0}=0.5, \sigma_{K}=0.3$. (B) The strength of competition exerted by the $l$ th product on the rate of diffusion of the $j$ th product with trait $\bar{x}_{j}$, as a slice of the competition function $\alpha\left(x_{j}, x_{l}\right)$ along the plane $x_{j}=\bar{x}_{j}$; straight lines on the $\left(x_{j}, x_{l}\right)$ plane: $x_{l}=x_{j}$ on which $\alpha\left(x_{j}, x_{l}\right)=1 ; x_{l}=\beta x_{j}$ on which $\alpha\left(x_{j}, x_{l}\right)$ is maximum; parameter values $\bar{x}_{j}=0.5, \beta=1.2, \sigma_{\alpha}=0.3$. 
$\left.\frac{\partial \bar{f}_{1}^{\prime}}{\partial x_{1}^{\prime}}\right|_{x_{1}^{\prime}=x_{1}}=\frac{r}{x_{1}}\left(\frac{1}{\sigma_{\alpha}^{2}} \ln \beta-\frac{1}{\sigma_{K}^{2}} \ln \frac{x_{1}}{x_{0}}\right)$.

Therefore, the AD canonical equation (see Eq. (12)) is

$\dot{x}_{1}=\left.\frac{1}{2} \mu_{1} \bar{n}_{1}\left(x_{1}\right) \sigma_{1}^{2} \frac{\partial \bar{f}_{1}^{\prime}}{\partial x_{1}^{\prime}}\right|_{x_{1}^{\prime}=x_{1}}$,

where $\mu_{1}$ and $\sigma_{1}$ are assumed to be independent of the trait. Eq. (20) admits a unique evolutionary equilibrium

$\bar{x}_{1}=x_{0} \beta^{\left(\sigma_{K} / \sigma_{\alpha}\right)^{2}}$,

which is always an attractor, since its associated eigenvalue is negative, because it has the same sign as

$\left.\frac{\mathrm{d}}{\mathrm{d} x_{1}}\left(\left.\frac{\partial \bar{f}_{1}^{\prime}}{\partial x_{1}^{\prime}}\right|_{x_{1}^{\prime}=x_{1}}\right)\right|_{x_{1}=\bar{x}_{1}}=-\frac{r}{\left(\bar{x}_{1} \sigma_{K}\right)^{2}}<0$.

Thus, in a market with a single product, repeated innovations and replacements of old variants with new ones drive the technological trait $x_{1}$ toward the equilibrium value $\bar{x}_{1}$. At $\bar{x}_{1}$ two selective forces acting on the market balance: the desire of a producer to be a better competitor by being distinct in technological content (under asymmetric competition) and the tendency to harvest on the median consumer in order to maximize the number of product items absorbable by the market (battle for market share). If, for example, higher technological traits are favored $(\beta>1)$, the economic intuition for reaching an equilibrium of zero technological change would be that there are cognitive, informational or physical limitations of consumers to absorb high technology, or simply budget constraints. Such limitations are modeled by the ratio $\sigma_{\alpha} / \sigma_{K}$ (see Eq. (21)). Notice that when $x_{1}$ is slightly larger [smaller] than $x_{0}$ and $\beta>1[\beta<1]$, a penetrating innovative product conquers the market, even if this implies a loss in product density.

In order to assess if the evolutionary equilibrium $\bar{x}_{1}$ marks the end of technological change or is a branching point, we can use the branching conditions (14) and (15), which in the present case are

$$
\begin{aligned}
& \left.\frac{\partial^{2} \bar{f}_{1}^{\prime}}{\partial x_{1}^{\prime 2}}\right|_{\substack{x_{1}^{\prime}=\bar{x}_{1} \\
x_{1}=\bar{x}_{1}}}=\frac{r}{\bar{x}_{1}^{2}}\left(\frac{1}{\sigma_{\alpha}^{2}}-\frac{1}{\sigma_{K}^{2}}\right)>0, \\
& \left.\frac{\partial^{2} \bar{f}_{1}^{\prime}}{\partial x_{1} \partial x_{1}^{\prime}}\right|_{\substack{x_{1}^{\prime}=\bar{x}_{1} \\
x_{1}=\bar{x}_{1}}}=\left.\frac{\mathrm{d}}{\mathrm{d} x_{1}}\left(\left.\frac{\partial \bar{f}_{1}^{\prime}}{\partial x_{1}^{\prime}}\right|_{x_{1}^{\prime}=x_{1}}\right)\right|_{x_{1}=\bar{x}_{1}}-\left.\frac{\partial^{2} \bar{f}_{1}^{\prime}}{\partial x_{1}^{\prime \prime}}\right|_{\substack{x_{1}^{\prime}=\bar{x}_{1} \\
x_{1}=\bar{x}_{1}}}<0 .
\end{aligned}
$$

Notice that, condition (24) is implied by the stability of $\bar{x}_{1}$ (see (Eq. 22)) and by condition (23). Thus, the equilibrium $\bar{x}_{1}$ is a branching point if the sensitivity of the competition function $\sigma_{\alpha}$ is smaller than the sensitivity $\sigma_{K}$ of the absorptive capacity function; of course, in the opposite case the evolutionary equilibrium is an ESS. Although the two sensitivities govern the dynamics of product densities on the market timescale (they are parameters of the market model (16)), they ultimately manifest themselves on the innovation timescale. Then, the difference $\sigma_{K}-\sigma_{\alpha}$ is a measure of the strength of diversification through technological change. Taking into account the geometric characteristics of the competition and absorptive capacity functions, we can say that our simple model suggests that technological branching occurs when the graph of the absorptive capacity (see Fig. 2A) is more flat than that of the competition function (see Fig. 2B). In other words, technological branching is expected in markets which are capable to absorb a rich variety of single technologies and/ or easily offer competition-safe niches even to rather similar products.

A relatively flat absorptive capacity would arise in situations when consumers are to a large extent indifferent to products satisfying a specific need. A typical example in the food market would be when consumers are indifferent to various sources of protein be it red meat, white meat, or meat imitations like soya products. The absorptive capacity function could also be interpreted as an aggregated utility function. In this case, the curvature, i.e., the second derivative of the utility function, is a measure for risk aversion. Hence a relatively flat absorptive capacity could be interpreted as a more risk taking representative agent (in this case consumer). Given such an interpretation less risk aversion would, according to our model, lead to product diversification.

On the other hand, competition functions are narrow when despite of a relatively small difference in the characteristic traits, the respective products weakly suffer from each other by competition. For example, the competition between "Breitling" and "Swatch" watches, or between stocks within the NASDAQ index, could be modeled by narrow competition functions.

A specific example of innovation dynamics under asymmetric competition $(\beta>1)$ is shown in Fig. 3 for the particular parameter setting (specified in the caption) for which the equilibrium $\bar{x}_{1}$ is a branching point. Starting with a single product with trait $x_{1}$ smaller than $x_{0}$, the trait first increases toward $\bar{x}_{1}$ (which is larger than $x_{0}$ since $\beta>1$, see Eq. (21)), as shown in Fig. 3A (upper panel) for $0<t<t_{2}$. On the innovation timescale, the equilibrium density $\bar{n}_{1}\left(x_{1}\right)$ (lower panel) first increases, as long as $x_{1}<x_{0}\left(0<t<t_{0}\right)$, and then declines when $x_{1}>x_{0}\left(t_{0}<t<t_{2}\right)$. The competition transients due to two particular successful innovations are shown in Fig. 3B on the market timescale. The first one (upper panel) corresponds to the market conditions holding at time $t_{1}$ in Fig. 3A: the density $n_{2}$ of the innovative product is initially very small, but then grows toward an equilibrium, while the density $n_{1}$ of the established product declines to zero, thus revealing that the innovative product substitutes the established one. In the lower panel of Fig. 3B, corresponding to the branching occurring at time $t_{2}$, the innovative product penetrates the market but does not substitute the established product, as 
A
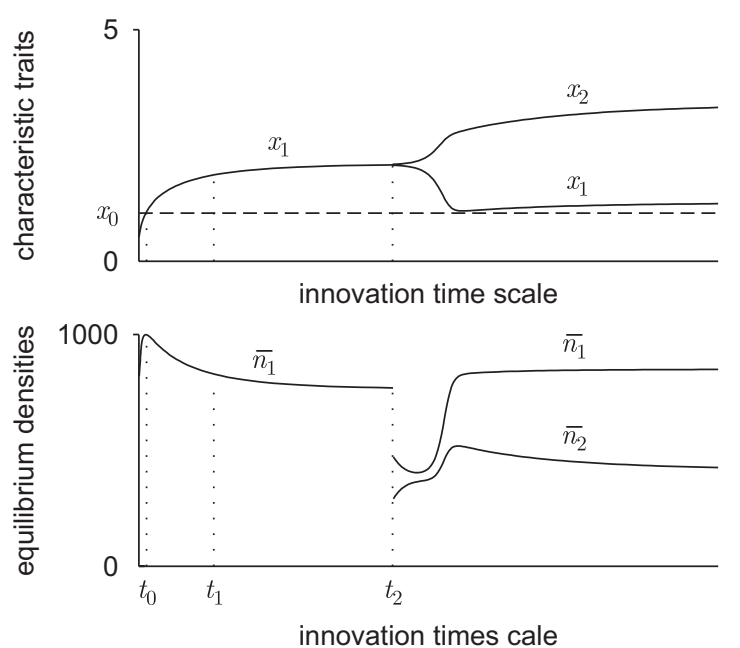

B
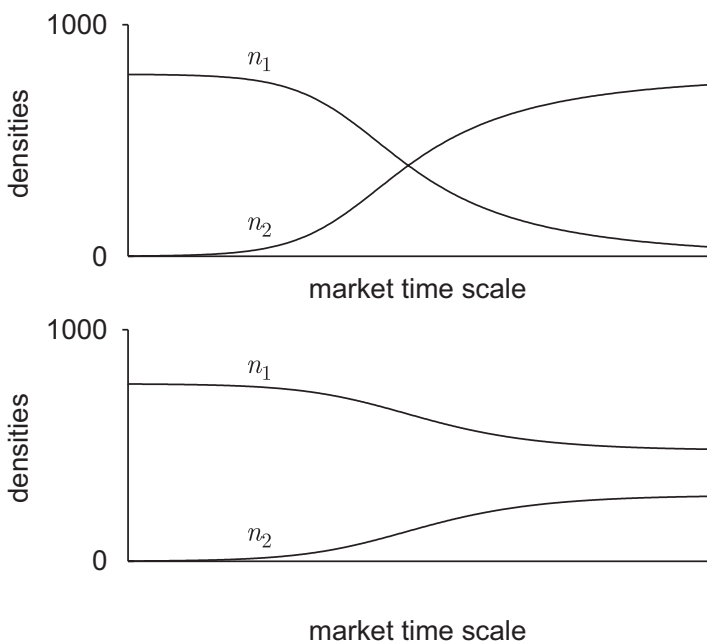

Fig. 3. Innovation dynamics under asymmetric competition $(\beta>1)$. (A) Characteristic traits (upper panel) and corresponding market equilibrium densities (lower panel) obtained through simulation of models and (20) and (25) with initial condition $x_{1}(0)=0.5<x_{0}$ (see dashed line). (B) Two examples of market dynamics obtained through simulation of model (16): product substitution (upper panel, $x_{1}=2, x_{2}=x_{1} * 1.01, n_{1}(0)=\bar{n}_{1}\left(x_{1}\right)=786.45$, and $n_{2}(0)=1$ ); branching (lower panel, $x_{1}=\bar{x}_{1}=2.0736, x_{2}=\bar{x}_{1} * 1.01, n_{1}(0)=\bar{n}_{1}\left(x_{1}\right)=766.49$, and $n_{2}(0)=1$ ); on the innovation timescale, these examples correspond to the instants denoted by $t_{1}$ and $t_{2}$ in (A). Parameter values: $\mu_{1}=\mu_{2}=1, \sigma_{1}=\sigma_{2}=1, r=1, \beta=1.2, \sigma_{\alpha}=0.5, K_{0}=1000, x_{0}=1, \sigma_{K}=1$.

shown by the graph of $n_{1}$, which declines but does not vanish.

After the branching has occurred, the innovation dynamics is given by the competition between a challenging innovative product and two distinct established products. The analysis of the two-products market can be performed by analyzing the corresponding second-order canonical equation. Denoting by $n_{i}^{\prime}$ and $x_{i}^{\prime}$ the density and trait of the innovative product and recalling Eqs. (7), (11), (16) and (17), then the two-products market equilibrium $\bar{n}\left(x_{1}, x_{2}\right)$, the invasion fitness $\bar{f}_{i}^{\prime}\left(x, x_{i}^{\prime}\right)$ and the selection gradient can be easily computed (only straightforward algebra is involved), and the result is the following:

$\bar{n}(x)=\frac{1}{1-\alpha\left(x_{1}, x_{2}\right) \alpha\left(x_{2}, x_{1}\right)}\left[\begin{array}{l}K\left(x_{1}\right)-\alpha\left(x_{1}, x_{2}\right) K\left(x_{2}\right) \\ -\alpha\left(x_{2}, x_{1}\right) K\left(x_{1}\right)+K\left(x_{2}\right)\end{array}\right]$,

$\bar{f}_{i}^{\prime}\left(x, x_{i}^{\prime}\right)=r\left[1-\frac{\alpha\left(x_{i}^{\prime}, x_{1}\right) \bar{n}_{1}\left(x_{1}, x_{2}\right)+\alpha\left(x_{i}^{\prime}, x_{2}\right) \bar{n}_{2}\left(x_{1}, x_{2}\right)}{K\left(x_{i}^{\prime}\right)}\right]$,

$$
\begin{aligned}
\left.\frac{\partial \bar{f}_{i}^{\prime}}{\partial x_{i}^{\prime}}\right|_{x_{i}^{\prime}=x_{i}}= & -\frac{r}{K\left(x_{i}\right)}\left[\left.\frac{\partial \alpha\left(x_{i}^{\prime}, x_{1}\right)}{\partial x_{i}^{\prime}}\right|_{x_{i}^{\prime}=x_{i}} \bar{n}_{1}\left(x_{1}, x_{2}\right)\right. \\
& \left.+\left.\frac{\partial \alpha\left(x_{i}^{\prime}, x_{2}\right)}{\partial x_{i}^{\prime}}\right|_{x_{i}^{\prime}=x_{i}} \bar{n}_{2}\left(x_{1}, x_{2}\right)\right] \\
& +\frac{r}{k^{2}\left(x_{i}\right)} \frac{\mathrm{d} K\left(x_{i}\right)}{\mathrm{d} x_{i}}\left[\alpha\left(x_{i}, x_{1}\right) \bar{n}_{1}\left(x_{1}, x_{2}\right)\right. \\
& \left.+\alpha\left(x_{i}, x_{2}\right) \bar{n}_{2}\left(x_{1}, x_{2}\right)\right],
\end{aligned}
$$

$i=1,2$, provided that $x_{1} \neq x_{2}$. Therefore, the second-order $\mathrm{AD}$ canonical equation (see Eq. (12)) is

$$
\dot{x}_{1}=\left.\frac{1}{2} \mu_{1} \bar{n}_{1}\left(x_{1}, x_{2}\right) \sigma_{1}^{2} \frac{\partial \bar{f}_{1}^{\prime}}{\partial x_{i}^{\prime}}\right|_{x_{i}^{\prime}=x_{1}},
$$

$$
\dot{x}_{2}=\left.\frac{1}{2} \mu_{2} \bar{n}_{2}\left(x_{1}, x_{2}\right) \sigma_{2}^{2} \frac{\partial \bar{f}_{2}^{\prime}}{\partial x_{i}^{\prime}}\right|_{x_{i}^{\prime}=x_{2}},
$$

where $\mu_{i}$ and $\sigma_{i}, i=1,2$, are assumed to be independent of the traits.

The relevant trajectory of model (25) is that originating from point $\left(\bar{x}_{1}, \bar{x}_{1}+\varepsilon\right)$ ( $\varepsilon$ very small), corresponding to the market condition holding at time $t_{2}$ in Fig. 3A, just after the transient depicted in the lower panel of Fig. 3B, i.e., just after the coexistence between products 1 and 2 has been established. The evolution of the traits $x_{1}$ and $x_{2}$ and that of the corresponding product densities $\bar{n}_{1}\left(x_{1}, x_{2}\right)$ and $\bar{n}_{2}\left(x_{1}, x_{2}\right)$ along such a trajectory are shown in Fig. 3A (upper and lower panels, respectively, $t>t_{2}$ ). The trait in one branch permanently increases, while in the other it initially decreases. This was expected because at a branching point the old and the new version of the product coexist under opposite selection pressures. Notice that the product associated with the upper branch (away from $x_{0}$ ) has a lower density, i.e., it is present in the market with fewer items, which, however, have a competitive advantage (recall that $\beta>1$ ) with respect to those in the lower branch, which resist competition being close to the trait $\left(x_{0}\right)$ that matches the median consumer. The figure also shows that the innovation dynamics drive the traits $x_{1}$ and $x_{2}$ of the two coexisting products toward a stable evolutionary 
equilibrium $\left(\bar{x}_{1}, \bar{x}_{2}\right)$. At this equilibrium the branching conditions (14) and (15) have been numerically tested by varying all the parameters of the model and the result is that again conditions (14) and (15) hold for both products if $\sigma_{K}>\sigma_{\alpha}$.

Of course, to understand the evolution of the system after the second branching, the analysis can be repeated, starting from the new (third-order) canonical equation. By means of a systematic numerical bifurcation analysis of the third- and higher-order canonical equations, we checked that the traits of $N$ coexisting products always converge toward a unique stable evolutionary equilibrium at which the branching conditions (14) and (15) hold for all products if $\sigma_{K}>\sigma_{\alpha}$ (more weakly as $N$ increases). This numerical analysis (available on request from the corresponding author) has been performed for wide ranges of all the parameters of the model (and various $N$ ) and has always brought to the same conclusion, namely that $\sigma_{K}>\sigma_{\alpha}$ implies the formation of rich clusters of products through a long sequence of technological branchings.

\section{Concluding remarks}

The purpose of this paper was to show how a recently proposed theory of evolutionary processes called adaptive dynamics (AD) could be used to explain the emergence of technological variety in economic systems. For this, we have first presented AD by adapting it to fit the properties of economic systems. Then, we have used AD for studying the evolution of technological traits and variety in an initially empty market subject to random marginal innovations. Our analysis is based on an abstract model which is intentionally very simple in order to obtain an analytically tractable problem. It is clear, however, that the analysis can be extended to much more realistic and complex situations, provided analytical tractability is not required.

Since some of the assumptions underneath $\mathrm{AD}$ are rather extreme, one must be careful in applying it to real situations. For example, technological change is an economic phenomenon taking place at different levels of temporal aggregation of the economy, involving individual consumers, businesses, markets, science, technology, formal and informal institutions and culture at wider levels (Hayek, 1967; Nelson, 1995; North, 1997). In real economic systems the market and innovation timescales are sometimes comparable, while $\mathrm{AD}$ requires that they are fully separated. However, quite frequently competition and technological change occur on contrasting timescales. Technological change slowly proceeds by means of continual replacement of established entities by novel ones on the micro-level, i.e., as a result of the fast interaction between economic actors on the market timescale. In consequence, $\mathrm{AD}$ provides a reasonable approximation of the process of technological change with the major promise of elucidating the long-term effects of the interplay between the single entities on a micro-level and the system's evolutionary fate on a macro-level.

Perhaps, the most relevant advantage of AD with respect to other theories is the possibility of clearly explaining the emergence of technological diversity and the formation of rich clusters of products. Indeed, it is empirically evident that technological diversity is a natural characteristic of industries undergoing technological change (see, e.g., Metcalfe, 1988; Bernard et al., 1994). However, there is little room for technological diversity in classical economic models: when the best practice is common knowledge it is instantly adopted and diversity has no theoretical justification (Jonard and Yildizoglu, 1999). Yet diversity is the basis for consumer choice and a prerequisite for competition. With the advent of evolutionary approaches and institutional approaches the role of variety, as called by Schumpeter, became a renascent topic. Stirling (1998) and various papers by Saviotti provide excellent reviews of the literature on the economics of diversity and shall not be repeated here. There is detailed empirical and theoretical work in areas like consumer characteristics, production processes and organizational forms, research strategies, competences and learning processes, technologies and modes of innovation, investor expectations and customer choice and competition.

Some of the evolutionary approaches to industrial dynamics explain the emergence of diversity by including uncertainty in the diffusion process, bounded rationality, imperfect information, demand slacks and endogenously determined market structures (Nelson and Winter, 1982; Dalle, 1998; Saviotti, 2001; Witt, 2001). However, at least in the limit case, in all models the selective pressures and the mechanical nature of diffusion lead to just one dominant technology. De Palma et al. (1998) show that in the presence of network externalities, diversity prevails as long as the effect of consumer heterogeneity overrules the effect of network externalities. These models, however, have to assume differentiated markets from the beginning and are not explicit on the emergence of diversity. Another popular hypothesis in economic theory is that local interaction (e.g., localization of imitation and localization of network externalities) is a condition for aggregate diversity (see, e.g., Nelson and Winter, 1982; Jonard and Yildizoglu, 1998a, b). In these models diversity is explained through geographically disjoint technological path dependencies leading to localized positive feedback economies such as agglomeration economies (Engländer, 1926; Ritschl, 1927; Palander, 1935; Arthur, 1990; Porter, 1990; Matsuyama, 1995). Earlier models in spatial economics that can be associated with the names of von Thünen (1826), Weber (1909), Christaller (1933), and Loesch (1941) see locational patterns as independent of history, inevitable, and thus lead to a unique equilibrium determined by, among others, geographical endowments, infrastructures and firms' needs. Geographically disjoint technological development is, however, in conflict with the empirical observations of spatial clusters, which consist of a complex 
of competing and complementary firms (or even branches within firms) involved in producing similar goods and services (see, e.g., Marshall, 1920; Dunning, 2000).

By contrast, AD allows for the evolution of technological diversity emerging in the same geographic area due to technological branching. The coexistence between marginally innovative and already established technologies is shown to be not possible as long as the penetration power of innovations is sufficiently strong (i.e., as long as the selection gradient does not vanish, see (11)). Only when technological change slows down at an evolutionary equilibrium the market opens up the possibility for more product diversity. Whether this is the case or not can be tested through the branching conditions (14) and (15), which only involve elements of the market model (2). The branching conditions fully characterize the market at the evolutionary equilibrium, whether it allows the coexistence of similar technologies (condition (15)), and whether its selective pressure diversifies them or not (condition (14)). Evolutionary equilibria are then classified as terminal points of technological change if branching is not possible (among which we find the ESS of evolutionary game theory), or as branching points. Repeated branching therefore represents a route toward product variety, and the identification of the market conditions which favor such a route is one of the question $\mathrm{AD}$ might help to elucidate. In our simple application, for example, we found that repeated branching is expected in market sectors which are not targeted on a specific technology and offer competition-safe niches even to rather similar products.

As this paper represents a first attempt to develop a dynamic model of technological change consistent with AD and compatible with several results from existing economic models, we have also shown that AD carries the potential to lead to new insights in the analysis of the metabolism and development of traits of economic systems. Many are, in fact, the evolutionary phenomena one can think to tackle by means of the AD approach. For example, apart from the increase in numbers of products through technological branching, we also see increase in product complexity. Illustrative for increasing complexity is the fact that the 1885 Rover safety bicycle consisted of about 500 parts, a modern car involves as many as 30,000 components and a Boeing 747 roughly 3.5 million (Ayres, 1988). Thus, product complexity could be modeled as trait of a suitable AD model, in order to investigate the economic conditions that lead to increasing complexity and their consequence on technological change and economic development.

Another scenario that can be interpreted by the $\mathrm{AD}$ approach is the convergence toward an underdevelopment trap, an ESS that can only be broken by a radical innovation. Modeling aggregate traits such as the level of technological development, one could use AD to show that developing countries are often destined to reach an ESS at a low level of technological development, from which they can hardly escape. In fact, for many developing countries, the relevant technological traits are defined more by epigenetic codes such as formal institutions and tacit social norms, which are more difficult to change radically as they acquire more and longerlasting information than individual agents. On these lines Greif (1994) argues that "the capacity of societal organization to change is a function of history, since institutions are combined of organizations and cultural beliefs, ... and past organizations and beliefs influence historically subsequent games, organizations and equilibria". The work of Hayek (1967) is more inspired by the idea of spontaneous evolution of conventions and institutions (Vromen, 1995) explaining radical changes of epigenetic codes.

Finally, outside the economic field, AD can be of great help for understanding various problems in social sciences. Even if many human behaviors are culturally transmitted, learned, or imitated (Boyd and Richerson, 1985), they can be treated as heritable traits: if differences in possible behaviors affect some measure of success, i.e., fitness, then behaviors can evolve through an innovation-selection process, where innovation simply means a behavioral change. Two relevant examples of behavioral evolution are fashion and cooperation.

The role of fashion is "identity display". The tendency to imitate certain stereotypes with desirable characteristics and the opposite tendency to diverge from them in order to proclaim an identity are contrasting selective forces. The trade-off between imitation and personalization might induce complex evolutionary dynamics of fashion traits, as shortly mentioned in Section 2 in the discussion of longterm evolutionary scenarios.

The evolution of cooperation among non-related individuals is one of the fundamental problems in social sciences. Experimental economists investigate this issue by public goods games, confronting individuals with the temptation to defect, i.e., to exploit the reward obtained from the public good without contributing to it. This is known as "The Tragedy of the Commons" (Hardin, 1968). Experimental results (Boyd and Richerson, 1992; Fehr and Gächter, 2000; Fischbacher et al., 2001; Fehr and Gächter, 2002) show that, without a mechanism for punishing defectors, groups of cooperators do better than groups of defectors, but defectors always outperform the cooperators in their group. In a recent theoretical study Hauert et al. (2002) describe the dynamics of the densities of cooperators, defectors and loners in the population, but do not allow their characteristic behavior to evolve. Thus, AD could be used to study the evolution of the propensity to cooperate, measured through a trait which is positive in the case of cooperation and negative in the case of defection.

In conclusion, beyond the intentionally simplified example presented in this paper, we believe that the $\mathrm{AD}$ approach is particularly suited to analyze technologysociety interactions.

\section{References}

Aghion, P., Howitt, P., 1992. A model of growth through creative destruction. Econometrica 60, 323-351 
Arthur, W.B., 1990. Silicon valley's locational clusters: when increasing returns imply monopoly. Mathematical Social Sciences 19, 235-251.

Ausubel, J.H., 1990. Hydrogen and the green wave. The Bridge 20, 17-22.

Ayres, R.U., 1988. Complexity, reliability, and design: manufacturing implications. Manufacturing Review 1, 26-35.

Bernard, J., Canter, U., Hnausch, H., Westerman, G., 1994. Detecting technological performance and variety. In: EUNETIC Conference, October, Strasbourg.

Boyd, R., Richerson, P.J. (Eds.), 1985. Culture and the Evolutionary Process. The University of Chicago Press, Chicago.

Boyd, R., Richerson, P.J., 1992. Punishment allows the evolution of cooperation (or anything else) in sizable groups. Ethology and Sociobiology 13, 171-195.

Brooks, H., 1980. Technology, evolution, and purpose. Daedalus 109, 65-81.

Burda, M., Wyplosz, Ch., 1997. Macroeconomics: A European Text. Oxford University Press, Oxford, UK.

Champagnat, N., Ferrière, R., Méléard, S., 2006. Unifying evolutionary dynamics: from individual stochastic processes to macroscopic models. Theoretical Population Biology 69, 297-321.

Christaller, W., 1933. Central Places in Southern Germany. Prentice-Hall, Englewood Cliffs, NJ.

Dalle, J.M., 1998. Local interaction structures, heterogeneity and diffusion of technological innovations. In: Lesourne, J., Orléan, A. (Eds.), Advances in Self-organization and Evolutionary Economics. Economica, London, pp. 240-264.

De Palma, A., Kilani, K., Lesourne, J., 1998. How network externalities affect product variety. In: Lesourne, J., Orléan, A. (Eds.), Advances in Self-organization and Evolutionary Economics. Economica, London, pp. 57-76.

Dercole, F., Rinaldi, S., 2002. Evolution of cannibalism: scenarios derived from adaptive dynamics. Theoretical Population Biology 62, 365-374.

Dercole, F., Rinaldi, S., 2008. Analysis of Evolutionary Processes: The Adaptive Dynamics Approach and its Applications. Princeton University Press, Princeton, NJ forthcoming.

Dercole, F., Ferrière, R., Rinaldi, S., 2002. Ecological bistability and evolutionary reversals under asymmetrical competition. Evolution 56, 1081-1090.

Dercole, F., Gragnani, A., Ferrière, R., Rinaldi, S., 2006. Coevolution of slow-fast populations: an application to prey-predator systems. Proceedings of the Royal Society of London B 273, 983-990.

Dieckmann, U., Law, R., 1996. The dynamical theory of coevolution: a derivation from stochastic ecological processes. Journal of Mathematical Biology 34, 579-612.

Dunning, J.H., 2000. Regions, globalization, and the knowledge economy: the issues stated. In: Dunning, J. (Ed.), Regions, Globalization, and the Knowledge Economy. Oxford University Press, Oxford, UK, pp. $1-29$.

Engländer, O., 1926. Kritisches und Positives zu einer allgemeinen reinen Lehre von Standort. Zeitschrift für Volkswirtschaft und Sozialpolitik, Neue Folge 5 (in German).

Fehr, E., Gächter, S., 1998. Reciprocity and economics: the economic implications of homo reciprocans. European Economic Review 42, 845-859.

Fehr, E., Gächter, S., 2000. Cooperation and punishment in public goods experiments. American Economic Review 90, 980-994.

Fehr, E., Gächter, S., 2002. Altruistic punishment in humans. Nature 415, 137-140.

Fischbacher, U., Gächter, S., Fehr, E., 2001. Are people conditionally cooperative? Evidence from a public goods experiment. Economics Letters 71, 397-404.

Fisher, J.C., Pry, R.H., 1971. A simple substitution model of technological change. Technological Forecasting and Social Change 3, 75-88.

Geritz, S.A.H., 2005. Resident-invader dynamics and the coexistence of similar strategies. Journal of Mathematical Biology 50, 67-82.

Geritz, S.A.H., Metz, J.A.J., Kisdi, E., Meszéna, G., 1997. The dynamics of adaptation and evolutionary branching. Physical Review Letters 78 , 2024-2027.
Geritz, S.A.H., Kisdi, E., Meszéna, G., Metz, J.A.J., 1998. Evolutionarily singular strategies and the adaptive growth and branching of the evolutionary tree. Evolutionary Ecology 12, 35-57.

Geritz, S.A.H., Gyllenberg, M., Jacobs, F.J.A., Parvinen, K., 2002. Invasion dynamics and attractor inheritance. Journal of Mathematical Biology 44, 548-560.

Greif, A., 1994. Cultural beliefs and the organization of society: a historical and theoretical reflection on collectivist and individualist societies. Journal of Political Economy 102, 912-950.

Grossman, G.M., Helpman, E., 1991. Innovation and Growth in the Global Economy. MIT Press, Cambridge, MA.

Grübler, A., 1998. Technology and Global Change. The Press Syndicate of the University of Cambridge, Cambridge, UK.

Hamilton, W.D., 1967. Extraordinary sex ratios. Science 156, 477-488.

Harberger, A.C., 1998. A vision of the growth process. American Economic Review 88, 1-32.

Hardin, G., 1968. The tragedy of the commons. Science 162, 1243-1248.

Hauert, C., De Monte, S., Hofbauer, J., Sigmund, K., 2002. Volunteering as Red Queen mechanism for cooperation in public goods games. Science 296, 1129-1132.

Hayek, F.A., 1967. Studies in Philosophy, Politics, and Economics. Routledge \& Kegan Paul, London.

Hodgson, G.M., 1997. The evolutionary and non-Darwinian economics of Joseph Schumpeter. Journal of Evolutionary Economics 7, 131-146.

Hofbauer, J., Sigmund, K., 1998. Evolutionary Games and Population Dynamics. Cambridge University Press, Cambridge, UK.

Jonard, N., Yildizoglu, M., 1998a. Interaction between local interactions: localized learning and network externalities. In: Cohendet, P., Llerena, P., Stahn, H., Umbhauer, G. (Eds.), The Economics of Networks: Interaction and Behaviours. Springer, Berlin, pp. 189-204.

Jonard, N., Yildizoglu, M., 1998b. Technological diversity in an evolutionary model with localized learning and network externalities. Structural Change and Economic Dynamics 9, 35-55.

Jonard, N., Yildizoglu, M., 1999. Sources of technological diversity. Cahiers de l'innovation no. 99030, CNRS, Paris.

Kelm, M., 1997. Schumpeter's theory of economic evolution: a Darwinian interpretation. Journal of Evolutionary Economics 7, 97-130.

Khibnik, A.I., Kondrashov, A.S., 1997. Three mechanisms of Red Queen dynamics. Proceedings of the Royal Society of London B 264, 1049-1056.

Kortum, S., 1997. Research, patenting, and technological change. Econometrica 65, 1389-1419.

Kuznetsov, Yu.A., 1998. Elements of Applied Bifurcation Theory, second ed. Springer, Berlin.

Loesch, A., 1941. The Economics of Location. Yale University Press, New Haven, CT.

Lowe, E.D., Lowe, J.W., 1990. Velocity of the fashion process in women's formal evening dress, 1789-1980. Clothing and Textiles Research Journal 9, 50-58.

Marshall, A., 1920. Principles of Economics, eighth ed. MacMillan, London.

Matsuyama, K., 1995. Complementarities and cumulative processes in models of monopolistic competition. Journal of Economic Literature $33,701-729$.

Maynard Smith, J., 1974. The theory of games and the evolution of animal conflicts. Journal of Theoretical Biology 47, 209-221.

Maynard Smith, J., 1982. Evolution and the Theory of Games. Cambridge University Press, Cambridge, UK.

Maynard Smith, J., Price, J., 1973. The logic of animal conflicts. Nature 246, 15-18

Metcalfe, J.S., 1988. The diffusion of innovation: an interpretative survey. In: Dosi, G., Freeman, C., Silverberg, R.N.G., Soete, L. (Eds.), Technical Change and Economic Theory. Francis Pinter, London, pp. 560-589.

Metz, J.A.J., Geritz, S.A.H., Meszéna, G., Jacobs, F.J.A., van Heerwaarden, J.S., 1996. Adaptive dynamics: a geometrical study of the consequences of nearly faithful reproduction. In: van Strien, S.J., Verduyn Lunel, S.M. (Eds.), Stochastic and Spatial Structures of Dynamical Systems. Elsevier Science, Burlington, MA, pp. 183-231. 
Nash, J., 1996. Essays on Game Theory. Edward Elgar, Cheltenham.

Nelson, R., 1995. Recent evolutionary theorizing about economic change. Journal of Economic Literature 33, 48-90.

Nelson, R., Winter, S., 1982. An Evolutionary Theory of Economic Change. Harvard University Press, Cambridge, MA.

North, D.C., 1997. The contribution of the new institutional economics to the understanding of the transition problem. WIDER Annual Lectures 1, World Institute for Development Economics Research, Helsinki.

Nowak, M.A., Sigmund, K., 1998. Evolution of indirect reciprocity by image scoring. Nature 393, 573-577.

Palander, T., 1935. Beiträge zur Standortstheorie. Almqvist \& Wiksells, Uppsala (in German).

Peretto, P., 1998. Technological change and population growth. Journal of Economic Growth 3, 238-311.

Porter, M.E., 1990. The Competitive Advantage of Nations. The Free Press, New York.

Ritschl, H., 1927. Reine und historische Dynamik des Standortes der Erzeugungszweige. Schmollers Jahrbuch 51, 813-870 (in German).

Romer, P.M., 1990. Endogenous technological change. Journal of Political Economy 98, 71-102.

Saviotti, P.P., 1996. Technological Evolution, Variety and the Economy. Edward Elgar, Cheltenham.
Saviotti, P.P., 2001. Variety, growth and demand. Journal of Evolutionary Economics 11, 119-142.

Schumpeter, J.A., 1912. The Theory of Economic Development. Dunker \& Humbolt, Leibzig (in German; English translation by Harvard University Press, 1934).

Segerstrom, P., 1998. Endogenous growth without scale effects. American Economic Review 88, 1290-1310.

Stirling, A., 1998. On the economics and analysis of diversity. SPRU Electronic Working Paper Series No. 28.

von Thünen, J.H., 1826. Der isolierte Staat in Beziehung auf Landwirtschaft und Nationalökonomie. Perthes, Hamburg (in German).

Vromen, J.J., 1995. Economic Evolution: An Enquiry into the Foundations of New Institutional Economics. Routledge, London.

Weber, A., 1909. The Theory of Location of Industries. The University of Chicago Press, Chicago.

Witt, U., 2001. Learning to consume: a theory of wants and of growth of demand. Journal of Evolutionary Economics 11, 23-36.

Young, A., 1998. Growth without scale effects. Journal of Political Economy 106, 41-63.

Ziman, J., 2000. Evolutionary models for technological change. In: Ziman, J. (Ed.), Technological Innovation as an Evolutionary Process. Cambridge University Press, Cambridge, UK, pp. 41-52. 